\title{
Minimally Invasive Plate Osteosynthesis of Pediatric Proximal Lateral Femoral Fractures with Locked Compression Plate
}

\author{
Syed Arsalan Haider Bukhari* \\ Associate Professor Army Med College \& examiner Orthopedics, CPSP, Chief of Army Staff Gold Medal, CMH Rawalpindi, Pakistan
}

Submission: July 25, 2017; Published: August 22, 2017

*Corresponding author: Syed Arsalan Haider Bukhari, Associate Professor Army Med College \& examiner Orthopedics, CPSP, Chief of Army Staff Gold Medal, CMH Rawalpindi, Royal national orthopedic hosp Stanmore, London, UK, Northern Punjab Rawalpindi, and Head of Orthopedics CMH Rawalpindi, Pakistan

\section{Abstract}

Introduction: Fractures of the lateral proximal region of femur in children are a very challenging injury, especially if they are comminuted. These are not only a major injury in these fragile patients, but they also cast a difficult treatment situation in face of variables like the growth plates, rapid growth rate, immature immune system, limited body reserves, and in case of improper or delayed treatment the high chances of malunions, non union, and limb shortening etc, so peculiar to these patients.

Aim: The aim of our retrospective short study was basically to evaluate the effectiveness of internal fixation with Locked Compression Plate applied with MIPO technique in proximal femur fractures in children. Eighteen children $(\mathrm{M}=16, \mathrm{~F}=2)$ between ages of 7 to 12 years who presented with Colonna type IV (Figure 1) fractures in the proximal region of femur between April 2009 to April 2010 (12 months) at CMH Lahore, were treated with $3.5 \mathrm{~mm}$ LCP fixation by MIPO technique. The locking head screw (LHS) was introduced through the LCP into the neck of femur, thereby not only getting a firm hold in the femoral neck but simultaneously keeping the screw short of the capital epiphyseal growth plate provided safety to it. In cases where the fracture was too proximal or comminuted and it was not possible to apply more than two LHS crews in proximal fragment, an attempt was made to apply a cancellous de rotation screw into the neck of femur through the proximal most hole of the LCP. In patients where the neck size allowed passage of only one LH screw, a supporting Hip spica was applied to avoid rotation. The idea of using LCP for such fractures was inspired from the application of LCP pediatric hip plate (Synthes ${ }^{\circledR}$ ), which is used after corrective osteotomies in children(Not available in Pakistan). Patients were evaluated to determine complications, clinical and radiological outcome.

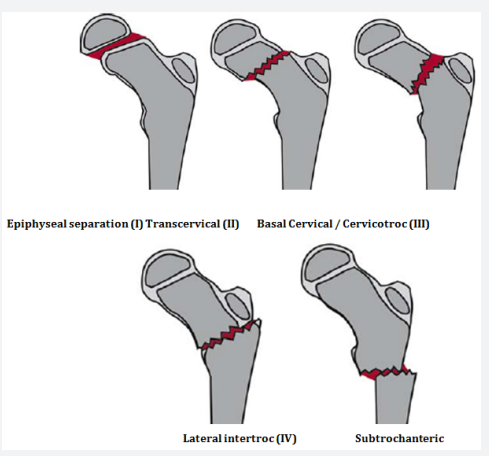

Figure 1: Delbet and Colonna Classification.

Results: All the patients were followed up at two weekly intervals for first month and then four weekly for 2 months and once six monthly till one year. At a mean post operative follow up of 3 months, good callus union was achieved in all cases. One patient (F) had mild coxa valga (due to plate over bend) and one developed superficial wound infection (M). In one patient (M) there was posterior displacement of a fracture fragment in a comminuted fracture. No avascular necrosis of the head of femur or premature physeal closure was seen. Fifteen patients had excellent results while three patients had good results in term of weight bearing and gait. The implant in all patients are planned to be removed after one year.

Conclusion: It was found in our study that the technique of applying LCP with MIPO technique in pediatric proximal femur fractures do hold a promise in treating these difficult and unstable fractures in children. The downside was that application of LCP by MIPO required experience with this method, size of neck in children limited the passage of two screws in many cases, chances of mal-alignment if plate bend was not adhered to strictly and cost constraint of implant.

Keywords: Pediatric; Lateral Proximal fracture femur; Locked compression plates 


\section{Introduction}

Children are the most active and untiring humans. These high reserves of energies make them highly prone to injuries. Child abuse and neglect too add to their share of causes of injuries in children. Among the array of various injuries which are sustained in childhood, fractures form a considerable part. In presence of more common pediatric fractures like supracondylar fracture of humerus, fractures of radius and ulna, fractures of distal radius, femoral shaft etc, the fractures of proximal femur in a pediatric patient present a challenging situation. These fractures have been well classified by Delbet and Colonna [1]. Of these the lateral proximal femur fractures or Colonna type IV, are very challenging due to the attached musculature which predisposes the fracture fragments to deformity. Moreover the quality of bone in children is fairly diverse from adults, being more inclined towards the dense bone especially in the proximal femoral area and is well enveloped by a strong periosteal sheath. This makes it necessary that high energy forces are imparted on such bones before breaking it. Events like fall from heights and trees, forceful direct blunt trauma, assault, and trauma due to vehicular hits etc, impart such forces to the thigh thereby severely damaging the proximal femur and surrounding soft tissue in children.

Pediatric lateral proximal femoral fractures not only confront the treating orthopedic surgeon with a taxing situation but also in face of the damaged thin, under developed and fragile soft tissues and musculature surrounding the fragments, the picture gets further complex. The need in such a scenario is to adopt a method of treatment that not only addresses these facts but also minimizes the chances of infection which is catastrophic once it develops in a pediatric bone. Similarly due to high and rapid healing potentials these cases are more prone to develop complications like malunion, nonunion, coxavara / valga, avascular necrosis and premature epiphyseal closure etc if the treatment is delayed or they are treated with unstable methods like k- wire fixations or simple traction etc, necessitating corrective osteotomies and multiple surgeries at a later stage. A diligent and prompt treatment of such potentially perilous fractures is the key to a successful outcome, a fact which has been illustrated in many studies [2].

Traditionally Type IV, intertrochanteric fractures were treated with skin or skeletal traction, and abduction spica cast. Internal fixation was considered in those cases only if the fracture could not be reduced and held in a spica cast. However with the advent of good implants and ancillary aids like image intensifier, new and novel techniques are emerging and LCP applied to these fractures with MIPO technique is also one of them.

\section{Materials and Methods}

Twenty children reported to the orthopedic department of CMH Lahore, between April 2009 to April 2010 with Type IV proximal femur fractures excluding two children with type IV proximal femur fractures but with Gustillo III injuries, eighteen patients with Type IV closed fractures of lateral proximal femoral region were included in the study. They were treated by fracture fixation with $3.5 \mathrm{~mm}$ and $4.5 \mathrm{~mm}$ Narrow LCP plate applied with MIPO method. Ten children had transverse pattern and six had oblique fracture. Two patients had comminuted pattern of fracture. Their ages ranged between 7-12 years. Out of the selected 18 patients, 16 were males and 2 were females. Selection criterions were the lateral type IV / proximal femur fractures, closed variety, and the patient being a child (less than 12 years). Trauma input included fall from height in 13 children $(\mathrm{M}=12, \mathrm{~F}=1)$, automobile accidents in $3(\mathrm{M}=3)$ and as a result of assault with a bamboo stick by uncle $(\mathrm{F}=1)$. Fifteen $(\mathrm{M}=14, \mathrm{~F}=1)$ patients were operated upon within 24-72 hours of injury. In three $(\mathrm{M}=2, \mathrm{~F}=1)$ patients the operative intervention was delayed by 6 days, the main reason of delay being the non availability of funds for implant / cost factor. Other associated injuries if any were managed on their own merit.

\section{Surgical Technique}

The patient was placed supine on the traction table and genitals were covered with lead shield. The child was secured in position then the image intensifier was positioned so that the visualization of the hip was possible in AP and axial view. Pre fixation AP and a lateral view were obtained with image intensifier and print outs were obtained. The fracture fragments were aligned in both views under image intensifier striving to achieve as best possible length, reduction and alignment. Angle of neck was corrected based on the info obtained from the measurements from the uninjured side as well as on the basis of the study of Lanz and Wacsmuth [3], which gave a detailed account of developmental angles of neck of femur in children. Plate length was determined by subcutaneous placement of a plate ensuring at-least three holes in each fragment. A longitudinal $2.5 \mathrm{~cm}$ proximal skin entry was made $1 \mathrm{~cm}$ below the tip of greater trochanter and gentle tunneling was done using the standard periosteal elevator, keeping in sub-muscular plane next to bone. Pre bend plate was introduced into the wound alongside the femur crossing the fracture site till the proximal end of the plate was brought to the desired position in line with the proximal femur in both AP and lat views.

A guide wire was passed into the lower central part of neck of femur through the drill sleeve locked into the second LCP hole and its position was evaluated in both views. At the same time it was ensured that the proximal combi hole if possible was kept approx 3-5 mm distal to the trochanteric epiphysis in AP view [4]. The fracture was reduced and the distal most hole of LCP in the distal fragment was secured with a locking head screw, under image guidance ensuring proper fracture alignment in both views. Following this a locking head screw was passed into the proximal most hole of LCP in the proximal fragment. Another locking head bolt was placed in the distal fragment 
(Figure 2). Guide wire which had been passed into the neck of femur was then removed and a hole was drilled through the drill guide staying well short of the proximal physeal plate. The screw depth into the neck was assessed with a depth gauge ensuring at all times that it falls well short of the basal capital epiphysis and the screw was locked into its hole, thereby obtaining good hold.
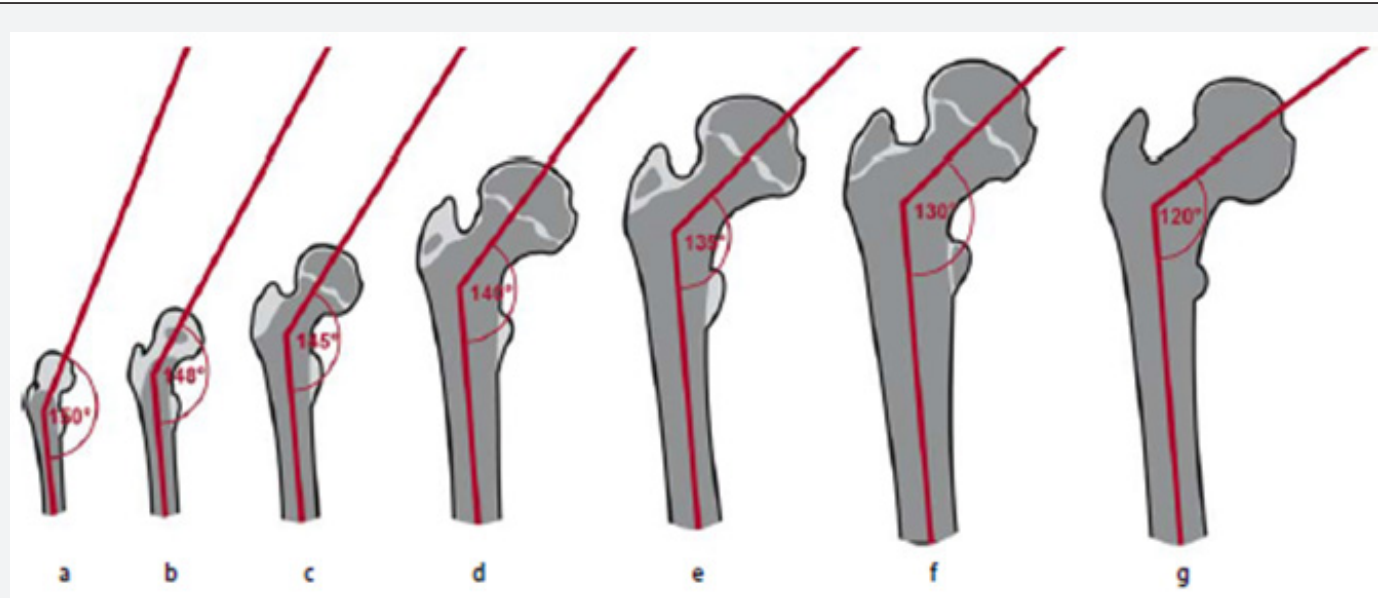

Figure 2: Lanz and Wacsmuth Angles. Development of the neck shaft angle: a. at birth, b. at the age of 1 year, c. 3 years, d. 5 years, e. 9 years, f. 15 years, g. in adulthood.

Rest of the LH screws was applied as necessary to secure a good hold on the fragments. Where allowed by the size of the neck of femur $(n=4)$, the cortical screw part of the most proximal combi hole was drilled and utilized for placement of a cancellous screw of $3.5 \mathrm{~mm}$ into the neck of the femur for better hold and derotation especially in comminuted fractures $(n=1)$. In one child with comminuted fracture pattern due to constraint of neck size it was not possible to place the proximal cancellous derotation screw. In these cases the Locking head screw was placed in the Centro-central position and a protective spica was applied post operatively. Patients were not allowed weight bearing for 6 weeks post operatively. Initially partial weight bearing was started. Full weight bearing was achieved in 14 children by $10^{\text {th }}$ week and in 4 children by $12^{\text {th }}$ weeks. Good union was seen in all by the $16^{\text {th }}$ week. All the patients were followed up at two weekly intervals for first month and then four weekly for next three months and once six monthly till one year. Plate removal was planned after completion of 18 months post operatively.

\section{Results}

Post operative evaluation in these patients revealed early callus in 12 children $(\mathrm{M}=11, \mathrm{~F}=1)$ at 4 weeks and appreciable early union at 10 weeks. Six children displayed appearance of callus at 6 weeks and early union at 16 weeks $(M=5, F=1)$. Good union was seen at 16 weeks follow-up. One of the patients $(\mathrm{F}=1)$ developed superficial wound infection which proved to be a stitch abscess and was identified and treated successfully at a very early stage. One patient $(\mathrm{F}=1)$ with comminuted fracture developed a mild coxa valga deformity mainly due to slight over angulation of the plate, but the difference did not merit any further treatment as it did not exceed 10 degrees. No shortening of limb length was seen. There were no incidence of loosening or breakage of the plate or screw pull out.No premature epiphyseal fusion occurred in any of the cases. It was observed that there was a fair chance of inter- fragmentary displacement in comminuted variety of proximal femur fractures in children when fixed with this method of treatment as was seen in one of our cases.

At the final assessment considering the Harris hip scores (10), 5 patients had an excellent result (90-100 points) while 2 patients had a good result (80-89points) and in one patient the results were fair (70-80). None of the patients had a poor result (less than 70).

\section{Discussion}

In most of the children the fractures of lateral proximal femur or Colonna type IV fractures are sustained due to fall from a height like roof or trees or blunt trauma sustained due to hit by a vehicle, domestic trauma or assault [4]. Most traditionally such fractures were treated by skin or skeletal traction or abduction spica cast which sometimes resulted in avoidable proximal femoral deformities like coxa vara or valga with limb length discrepancies. Internal fixation was considered necessary if the fracture could not be reduced satisfactorily and held in a spica cast. With the development of latest implants, advancements in understanding of fracture managements [3]; and invention of ancillary aids like image intensifier etc, novel methods like MIPO [5] or implants like LCP are becoming common. More over the comminuted variety of fractures when opened up may end up with complications like infection, delayed union or non union which can be effectively avoided by more "biologic" methods of reduction like MIPO, involving the use of indirect techniques and new plate designs.

Such methods preserve the blood supply to the injured bone, improve the rate of fracture healing, decrease the need 
for bone grafting, and lower the incidence of infection and other complications. Percutaneous plating appears to be the next step in the evolution of biologic plating. With these techniques, the fracture is reduced indirectly, and plates are placed into sub muscular or subcutaneous tunnels through limited skin incisions. This may result in less surgical trauma to tissues and further improvements in clinical results compared with current methods of plate insertion [6]. The concept of LCP has revolutionized the orthopedic fixations and its use in fragile and osteoporotic bones is remarkable in terms of its success [7]. Pediatric diaphyseal femur fractures have been fixed at some centers with 4.5-mm narrow low-contact dynamic compression plate plates with by MIPO i.e. minimal exposure for plate entry and percutaneous screw placement which has greatly facilitated the treatment of these fractures [8].

Use of such plates is not very common in managing lateral proximal femoral fractures of femur in children and a few have been reported in literature so far [9]. These plates provide an early, stable internal fixation in form of a 3.5 LCP which can be contoured as per the dictates of the neck shaft angle. Minimally invasive plate osteosynthesis too has revolutionized the fracture fixation especially in comminuted fractures [10]. In such cases not only helps in retaining the soft tissue envelope around the fragments, but also prevents the loss of fracture hematoma which in turn dramatically reduces the chances of infection, delayed union or non union [11] Careful and meticulous reduction also goes a long way in prevention of malunion, though one should remember that LCP application with minimally invasive plate osteosynthesis is not a simple procedure [12] [13], and it requires a learning curve. Adequate preoperative planning too is mandatory, as well as accurate surgical timing.

It has been seen that in early postoperative period the children should be preferably kept bed bound for at least 04 weeks as these over energetic and non compliant patients that the children are, can seriously jeopardize the entire exercise of fracture fixation. Some people recommend that they should be kept on traction even after stable fixation because they could not rely on small children to keep strictly non weight bearing. Infection is a dreaded complication of this fracture. Overall reported incidence in various series has been from $2 \%$ to as high as $21 \%$, if overzealous dissection or fragment exposure was carried out [14]. It has been proposed that infection in these cases results from the fragmentary interruption of blood supply during dissection or infection of fractures hematoma which can seep deep into the tissues during manipulations [15]. Moreover attempts to perfectly reduce and fix such fractures further can lead to infection by devascularizing the fracture fragments.

Nonunion is another devastating complication of these fractures. The factors again which have been implicated are poor reduction, improper immobilization, over dissection or the adoption of conservative treatment. Various series particularly early ones have reported an incidence of AVN (6.7\%) [16]. Our study however does not report a single case of nonunion possibly because all the cases were treated with proper anatomical reduction and stable early fixation with MIPO/LCP fixation. Delayed union, coxavara/ valga and premature epiphyseal closure are other complications which can occur. Our series had only two cases of a mild coxa valga because of iatrogenic over bending of the LCP due to miscalculation, though the valgus exaggeration did not exceed 10 degrees.

\section{Conclusion}

This method of early, stable internal fixation of lateral proximal femur fractures, utilizing contoured $3.5 \mathrm{~mm}$ LCP bend to measurements, coupled with MIPO was found to be technically demanding but a safe and a gratifying technique in terms of results in our series as was seen by Sink et al. too [17]. The downside was chances of mal-alignment if meticulous angle of the neck or inter-fragmentary alignment was not carried out during the fixation resulting in leg length discrepancy. Original implant (Synthes $®$ ) cost was also another constraining factor. Based on our experience LCP application by MIPO technique does hold a promise and seemingly can be safely extended to manage pediatric proximal femur fractures to achieve good fracture union. We highly recommend larger series and multicentric trials on similar lines in managing such fractures, so as to further elucidate the reliability and validity of this procedure $[18,19]$.

\section{References}

1. Colonna PC (1929) Fractures of the neck of the femur in children. Clin Orthop 6: 793-797.

2. Cheng JC, Tang N (1999) Decompression and stable internal fixation of femoral neck fractures in children can affect the outcome. J Pediatric Orthop 19: 338-343.

3. Hughes LO, Beatty JH (1994) Fractures of neck and proximal fractures of femur in children; current concepts review. J Bone Joint Surg (Am) 76: 283-292.

4. Mirdad T (2002) Fractures of neck of femur in children. An experience at Aseer Central Hospital, Abha, Saudi Arabia. Injury 33: 823-827.

5. Hedequist DJ, Sink E (2005) Technical aspects of bridge plating for pediatric femur fractures. J Orthop Trauma. 19(4): 276-279.

6. Ağuş H, Kalenderer O, Eryanilmaz G, Omeroğlu H (2003) Biological internal fixation of comminuted femur shaft fractures by bridge plating in children. J Pediatr Orthop 23(2): 184-189.

7. Hasenboehler EA, Agudelo JF, Morgan SJ, Smith WR, Hak DJ, et al. (2007) Treatment of complex proximal femoral fractures with the proximal femur locking compression plate. Orthopedics 30(8): 618-23.

8. Manual of LCP Pediatric Hip Plate. For osteotomy and trauma applications in the proximal femur. (AO/ASIF/Synthes). 036.000.848 Synthes 2007 LCP, Stardrive and Vario. Solothurn.

9. Cantu RV, Koval KJ (2006) The use of locking plates in fracture care. J Am Acad Orthop Surg 14(3): 183-90.

10. Harris WH (1969) Traumatic arthritis of the hip. An end-result study using a new method of result evaluation. J Bone Joint Surg Am 51(4): 737-55. 
11. Krettek C, Müller M, Miclau T (2001) Evolution of minimally invasive plate osteosynthesis (MIPO) in the femur. Injury 32(3): SC14-23.

12. Collinge CA, Sanders RW (2000) Percutaneous plating in the lower extremity. J Am Acad Orthop Surg 8(4): 211-216.

13. Snow M, Thompson G, Turner PG (2008) A mechanical comparison of the locking compression plate (LCP) and the low contact-dynamic compression plate (DCP) in an osteoporotic bone model. J Orthop Trauma 22(2): 121-125.

14. Nayeemuddin M, Higgins GA, Bache E, Ohara J, Glitheroe P (2009) Complication rate after operative treatment of pediatric femoral neck fractures. J Pediatr Orthop B.

15. Sink EL, Hedequist D, Morgan SJ, Hresko T (2006) Results and technique of unstable pediatric femoral fractures treated with sub muscular bridge plating. J Pediatr Orthop 26(2): 177-181.
16. Chrisovitsinos JP, Xenakis T, Papakostides KG, Skaltsoyannis N, Grestas A, et al. (1997) Bridge plating osteosynthesis of 20 comminuted fractures of the femur. Acta Orthop Scand Suppl 275: 72-76.

17. Lanz T von, Wachsmuth W (1972) Praktische Anatomie, I. Bd 4. Teil:Bein und Statik. Springer, Berlin Heidelberg, New York, USA.

18. Collinge CA, Sanders RW (2000) Percutaneous plating in the lower extremity. J Am Acad Orthop Surg 8(4): 211-216.

19. Collinge CA, Sanders RW (2000) Percutaneous plating in the lower extremity. J Am Acad Orthop Surg 8(4): 211-216.

\section{Your next submission with Juniper Publishers will reach you the below assets}

- Quality Editorial service

- Swift Peer Review

- Reprints availability

- E-prints Service

- Manuscript Podcast for convenient understanding

- Global attainment for your research

- Manuscript accessibility in different formats

( Pdf, E-pub, Full Text, Audio)

- Unceasing customer service

Track the below URL for one-step submission https://juniperpublishers.com/online-submission.php 